\title{
The Emerging Role of Calcium-activated Chloride Channel Regulator 1 in Cancer
}

\author{
DINGYUAN HU ${ }^{1,2}$, DANIEL ANSARI ${ }^{2}$, MONIKA BAUDEN $^{2}$, QIMIN ZHOU $^{2}$ and ROLAND ANDERSSON ${ }^{3}$ \\ ${ }^{1}$ Department of Gastroenterology, The Second Affiliated Hospital and Yuying \\ Children's Hospital of Wenzhou Medical University, Wenzhou, P.R. China; \\ ${ }^{2}$ Department of Clinical Sciences Lund, Surgery, Faculty of Medicine, Lund University, Lund, Sweden; \\ ${ }^{3}$ Department of Clinical Sciences Lund, Surgery, Skane University Hospital, Lund University, Lund, Sweden
}

\begin{abstract}
Calcium-activated chloride channel regulator 1 (CLCA1) belongs to a group of secreted self-cleaving proteins, which activate calcium-dependent chloride channels. CLCA1 has been shown to participate in the pathogenesis of inflammatory airway diseases such as asthma. Recently, additional functions of CLCAl have been unveiled, including its metalloprotease property and involvement in mucus homeostasis and immune modulation. Emerging evidence suggests that CLCAI may also be involved in the pathophysiology of colorectal, pancreatic and ovarian cancer. There is growing interest in utilizing CLCA1 as a diagnostic, prognostic and predictive biomarker, as well as a potential therapeutic target. In this review, the functional role of CLCA1, with a particular focus on cancer, is described.
\end{abstract}

Calcium-activated chloride channel regulators (CLCAs), also called chloride channel accessory proteins, are a family of secreted self-cleaving proteins, which activate calciumdependent chloride channels. CLCAs have been implicated in the regulation of cell proliferation, cell migration and metastasis and are believed to be emerging therapeutic targets in cancer (1-3). The human genome encodes three functional CLCAs, including CLCA1, CLCA2, and CLCA4. CLCA3 is a truncated pseudogene and does not encode a protein (4). Among the CLCAs, CLCA1 possesses unique characteristics, which

This article is freely accessible online.

Correspondence to: Roland Andersson, $\mathrm{MD}, \mathrm{PhD}$, Professor, Department of Surgery, Clinical Sciences Lund, Lund University and Skåne University Hospital, SE-221 85 Lund, Sweden. Tel: +46 46172359, e-mail: roland.andersson@med.lu.se

Key Words: Calcium-activated chloride channel regulator 1, CLCA1, cancer, biomarker, review. attribute to this protein a role in mucus homeostasis. CLCA1 is well studied due to its link to development of inflammatory airway disease (5). However, recent data indicate that CLCA1 may also be involved in neoplasia $(6,7)$. Consequently, CLCA1 has been suggested as a novel biomarker and a potential therapeutic target for various malignancies. Here, a comprehensive summary of the molecular structure, function and regulation of CLCA1 in cancer is provided.

\section{Molecular Characterization and Function}

The molecular characterization and function of human CLCA1 was first described by Gruber et al. in 1998 (8). The 31,902-bp gene, CLCA1, is located on chromosome 1p22-31 and is preceded by a canonic promoter region that contains an L1 transposable element. The encoded protein is expressed as a $125-\mathrm{kDa}$ precursor protein that is processed to yield two cell-surface-associated subunits, a $90-\mathrm{kDa}$ protein and a group of 37- to 41-kDa proteins (8) (Figure 1). The $90-\mathrm{kDa}$ subunit includes four transmembrane domains. However, the information regarding the crystal structure of intact CLCA1 and its fragments is currently not available.

CLCA1 was initially considered to be a regulator of calcium-activated chloride channel $(\mathrm{CaCC})$ proteins, which are involved in intracellular signaling events and activate specific cellular responses, including cancer-related proliferation, apoptosis, migration and angiogenesis (9). Secreted CLCA1 has been demonstrated to be a direct modulator of another calcium-dependent chloride channel, TMEM16A $(10,11)$. CLCA1 can stabilize TMEM16A on the cell surface and prevent its internalization, thus activating chloride currents $(10,11)$. CaCC currents are modulated by the N-terminal fragment of CLCA1 (1). Expression of recombinant CLCA1 protein in HEK 293 cells resulted in an increase in whole-cell calcium-sensitive chloride currents, thereby mediating a $\mathrm{Ca}^{2+}$ activated $\mathrm{Cl}$ - conductance in the human intestine (8). 
Moreover, by protein structure prediction and structure modeling, a zinc metal-dependent hydrolase domain in CLCA1 was discovered (12). These findings were further supported by experimental evidence $(1,13)$. Indeed, Yurtsever and colleagues unambiguously demonstrated that CLCA1 is a novel zinc metalloprotease that mediates selfcleavage (1). This self-cleavage is indispensable for $\mathrm{CaCC}$ activation. This reaction is probably carried out by exposing the N-terminal fragment of CLCA1, which could activate $\mathrm{CaCCs}$ by direct interaction with the channel (1). Moreover, structural components of colonic mucus have also been suggested as substrates for CLCA1 (13), implying that CLCA1 plays a role similar to matrix metalloproteases.

CLCA1 was also connected to CLCA1-MAPK signaling pathway responsible for IL-13-induced airway mucus production (14). Human CLCA2 or mouse CLCA1 has been shown to facilitate cell adhesion via interaction with $\beta 4$ integrin on the surface of melanoma cells and also to promote metastatic growth $(15,16)$. Human CLCA1, however, does not present this characteristic as the $\beta-4$ integrin binding motif is disrupted (17). Interestingly, recent studies propose that CLCA1 also takes part in mucus homeostasis and immune modulation.

\section{Mucus Homeostasis}

Of the three CLCA gene products expressed at mucosal surfaces (CLCA1, CLCA2, and CLCA4), only CLCA1 appears to regulate mucin gene expression and consequent mucus production (14). The proteolytic and ion currentrelated activities of CLCA1 make it an interesting candidate for regulation of mucus dynamics and homeostasis. In the trachea, Alevy and colleagues delineated an IL-13-CLCA1MAPK13-MUC5AC signaling pathway for mucus regulation, in which CLCA1 expression and secretion were activated by IL-13 in response to allergens or virus, and consequently activated MAPK13 and mucin production, especially MUC5AC (14). In the intestine, CLCA1 has been recently demonstrated to cause increased mucus thickness and penetrability through its proteolytic activity, independently of the ion conductance or mucus secretion (13).

\section{Immune Modulation}

The role of CLCA1 in immune response is well-studied in asthma. Increased mRNA expression of hCLCA1 was found in the epithelium of patients with asthma compared with controls (18). One study revealed that gob-5 (mouse counterpart CLCA1) is a key molecule in the induction of murine asthma, being involved in airway hyperresponsiveness and mucus overproduction (19). Ching and colleagues have found that CLCA1 released from epithelial cells can activate airway macrophages through the induction of cytokine

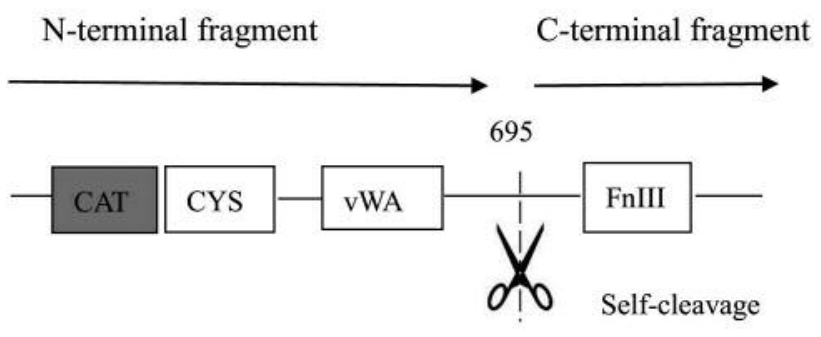

Figure 1. Schematic protein structure of human CLCA1. CLCA1 includes CAT, CYS, vWA and FnIII domains. Self-cleavage capability in the CAT domain allows CLCA1 to be split into two fragments; the $N$-terminal fragment and the C-terminal fragment. The $N$-terminal fragment is responsible for the activation of the calcium-activated chloride channel. CAT: Metalloprotease catalytic domain; CYS: Cysrich domain; vWA: von Willebrand type A domain; FnIII: fibronectin type III domain.

expression, such as IL-1 $\beta$, IL-6, TNF- $\alpha$ and IL-8, thereby inducing a pro-inflammatory response in the airway (20). However, the finding that hydrolase-inactive mutant CLCA1 retains the capability to activate macrophages suggested that this function was not mediated by the activation of $\mathrm{CaCC}(20)$. Further studies are, thus, needed to unveil the underlying mechanism. As an immune modulator, involving macrophage contribution, is strongly implicated in tumor progression (21, 22). Although these findings shed a strong light on the participation of CLCA1 in tumorigenesis, such a role awaits future investigation.

\section{Expression and Distribution in Humans}

It has been found that CLCA1 can be shed from the cell membrane and be secreted into the circulation $(17,23)$. This allows CLCA1 to serve as a candidate biomarker in serum and biofluids, as proposed in the case of colorectal cancer (CRC) (7) and pancreatic cancer (23). CLCA1 is mainly expressed in the large and small intestine and appendix, especially in crypt cells (8). CLCA1 has also been detected in diseased lung (24) and healthy mucosal tissues, such as the uterus, testis and kidneys (25).

\section{Role in Cancer}

Ion channels in general, and $\mathrm{Ca}^{2+}$-activated chloride channels in particular, are known to be involved in the regulation of cell proliferation, cell migration and metastasis and are believed to be important emerging drug targets in cancer (2, 3). A calcium-dependent chloride channel, TMEM16A, has also been proposed to contribute to tumor growth and invasion in lung cancer, prostate cancer and head and neck squamous cell carcinomas (26-29). Since CLCA1 has been demonstrated to be a direct modulator of TMEM16A, its role in tumorigenesis is increasingly recognized. A growing body 
of evidence suggests that CLCA1 may participate in the tumorigenesis of CRC, pancreatic cancer and ovarian cancer. CLCA1 has been proposed as a potential biomarker for diagnosis, prognosis and treatment response, as well a potential therapeutic target in cancer.

Colorectal cancer. CLCA1 is mostly abundant in the intestine. Bustin et al. have reported that CLCA1 expression is downregulated in CRC (30). Recent studies further confirmed the decreased expression of CLCA1 in CRC compared with adjacent normal tissue by immunohistochemistry at the tissue level, and by ELISA in serum $(7,31,32)$. Furthermore, serum and tissue CLCA1 levels have been inversely correlated with CRC histological grade, metastasis and tumor stage $(7,33)$. Moreover, Yang et al. have found that low expression of CLCA1 is associated with a poor prognosis (i.e. more frequent disease recurrence and decreased survival) in CRC, which may provide information for selection of patients subjected to adjuvant chemotherapy (33). These results are in line with the TCGA database, in which low mRNA expression of CLCA1 was associated with a poor prognosis in 597 patients with CRC (34) (https://www.proteinatlas.org/). However, Chen et al. have reported that high CLCA1 expression, rather than low CLCA1 expression, predicted poor prognosis in patients with rectal cancer receiving chemoradiotherapy (35). This discrepancy may originate from administration of treatment before sampling, sample size, patient characteristics, statistics and different scoring of immunohistochemical staining. More studies are needed to clarify the effect of CLCA1 levels on the prognosis of CRC. In conclusion, CLCA1 may serve as a potential biomarker for diagnosis, prognosis and the treatment response of CRC patients.

The mechanistic role of CLCA1 in CRC has also been investigated. Knockdown of CLCA1 in Caco-2 cell line has been shown to inhibit cell differentiation and promote cell proliferation (22). Further results from in vitro experiments suggested that CLCA1 may function as a tumor suppressor in CRC by inhibiting the Wnt/beta-catenin signaling pathway and the epithelial-mesenchymal transition process, while in vivo overexpression of CLCA1 led to inhibition of proliferation and metastasis (14). Furthermore, CLCA1 has been demonstrated to closely regulate TMEM16A, which has been proposed to participate in growth, migration and invasion of metastatic CRC cells (36-38). Transcription of CLCA1 has also been shown to persistently correlate with transcription of $c-m y c$, a proto-oncogene whose product is closely involved in the regulation of cell proliferation and apoptosis (30). However, the underlying mechanism remains to be understood.

Pancreatic cancer. The expression pattern and underlying biology of CLCA1 in pancreatic cancer are less known. In the Human Protein Atlas, a public protein expression database, the expression of CLCA1 in both normal and cancerous pancreas tissue was absent (34). In contrast, a study performed by our group showed that CLCA1 expression appeared in more than half of pancreatic cancer specimens (39). By mass spectrometry-based proteomics, low levels of CLCA1 were significantly associated with a poor outcome and CLCA1 was thus suggested as a potential prognostic biomarker for pancreatic cancer (6). A further validation study by immunohistochemistry, which involved 140 patients with pancreatic cancer, revealed that low expression of CLCA1 was independently correlated with shorter disease-free survival (39). The expression of CLCA1 was not associated with any clinical parameters of pancreatic cancer, including histological grade, tumor size and staging, indicating that CLCA1 may serve as independent prognostic biomarker for this malignancy. CLCA1 has also been proposed as a supportive marker to distinguish between cystic precursor lesions and pancreatic cancer using cyst fluid samples (23). The role of CLCA1 in mucus homeostasis leads us to suspect that CLCA1 may also be involved in the progression from mucinous cystic neoplasms and intraductal papillary mucinous neoplasms, two precursor forms of pancreatic cancer, to pancreatic cancer.

Pancreatic cancer is characterized by a dense and heterogeneous tumor microenvironment, which drives tumor progression and resistance to therapy $(40,41)$. Several matrix metalloproteases have been closely implicated in pancreatic cancer and have been proposed as therapeutic targets (4245). The metalloprotease property of CLCA1 might share a similar role in pancreatic cancer. While the role of CLCA1 in pancreatic cancer remains unclear, its target modulator, TMEM16A, was found to be overexpressed in pancreatic cancer cells and to promote cell migration (46).

Ovarian cancer. Ion channels are closely involved in ovarian cancer development and progression and may also be responsible for multidrug resistance (47). In particular, voltage-gated, volume-regulated and intracellular chloride channels have been detected both in vitro and in vivo in ovarian cancer and shown to be involved in proliferation, adhesion and invasion (47). By mass spectrometry-based proteomics, Musrap et al. compared the proteome profiles of aggregate-forming ovarian cancer cells with those of cells grown as monolayers and identified CLCA1 as the most upregulated protein among the thirteen candidates in cells with aggregate formation (48). Furthermore, treatment with a chloride channel blocker or knockdown of CLCA1 by siRNAs resulted in a reduced ability of cancer cells to form aggregates, which is considered crucial for the development of metastasis. These findings highlight the importance of CLCA1 in ovarian cancer progression and its resistance to chemotherapy and may be a novel therapeutic target for this type of malignancy. Further investigation is warranted to delineate the role of CLCA1 in ovarian cancer biology. 


\section{Conclusion}

Ion channels in general, and $\mathrm{Ca}^{2+}$-activated chloride channels in particular, represent emerging cancer biomarkers and potential drug targets. The role of CLCA1 has expanded from inflammatory airway disease to other conditions, including cancer. Moreover, the latest understanding of the molecular structure and function of CLCA1, especially its secreted form which has metalloprotease activity, and its involvement in mucus homeostasis and immune modulation, has drawn attention to the utilization of CLCA1 as a potential biomarker and even as a therapeutic target in cancer. However, additional knowledge concerning the underlying mechanisms and function of CLCA1 as a signaling molecule is necessary. Thus, clinical and pre-clinical studies concerning its function as a biomarker and therapeutic target are warranted.

\section{Conflicts of Interest}

The Authors report no conflicts of interest regarding this study.

\section{Authors' Contributions}

D.H. wrote the manuscript with support from D.A.; M.B. and Q.Z. contributed to the final revision of the manuscript; R.A. supervised the project and conceived the original idea.

\section{References}

1 Yurtsever Z, Sala-Rabanal M, Randolph DT, Scheaffer SM, Roswit WT, Alevy YG, Patel AC, Heier RF, Romero AG, Nichols CG, Holtzman MJ and Brett TJ: Self-cleavage of human clcal protein by a novel internal metalloprotease domain controls calcium-activated chloride channel activation. J Biol Chem 287(50): 42138-42149, 2012. PMID: 23112050, DOI: 10.1074/jbc.M112.410282

2 Lang $F$ and Stournaras C: Ion channels in cancer: Future perspectives and clinical potential. Philos Trans R Soc Lond B Biol Sci 369(1638): 20130108, 2014. PMID: 24493756, DOI: $10.1098 / \mathrm{rstb} .2013 .0108$

3 Stock $\mathrm{C}$ and Schwab A: Ion channels and transporters in metastasis. Biochim Biophys Acta 1848(10 Pt B): 2638-2646, 2015. PMID: 25445667, DOI: 10.1016/j.bbamem.2014.11.012

4 Gruber AD and Pauli BU: Molecular cloning and biochemical characterization of a truncated, secreted member of the human family of $\mathrm{Ca}^{2+}$-activated Cl- channels. Biochim Biophys Acta 1444(3): 418-423, 1999. PMID: 10095065.

5 Patel AC, Brett TJ and Holtzman MJ: The role of CLCA proteins in inflammatory airway disease. Annu Rev Physiol 71: 425-449, 2009. PMID: 18954282, DOI: 10.1146/annurev.physiol. 010908.163253

6 Hu D, Ansari D, Pawlowski K, Zhou Q, Sasor A, Welinder C, Kristl T, Bauden M, Rezeli M, Jiang Y, Marko-Varga G and Andersson R: Proteomic analyses identify prognostic biomarkers for pancreatic ductal adenocarcinoma. Oncotarget 9(11): 9789-9807, 2018. PMID: 29515771, DOI: 10.18632 /oncotarget.23929
7 Li X, Hu W, Zhou J, Huang Y, Peng J, Yuan Y, Yu J and Zheng S: CLCA1 suppresses colorectal cancer aggressiveness via inhibition of the WNT/beta-catenin signaling pathway. Cell Commun Signal 15(1): 38, 2017. PMID: 28974231, DOI: 10.1186/s12964-017-0192-z

8 Gruber AD, Elble RC, Ji HL, Schreur KD, Fuller CM and Pauli BU: Genomic cloning, molecular characterization, and functional analysis of human clca1, the first human member of the family of $\mathrm{Ca}^{2+}$-activated $\mathrm{Cl}$ - channel proteins. Genomics 54(2): 200-214, 1998. PMID: 9828122, DOI: 10.1006/geno. 1998.5562

9 Prevarskaya N, Skryma R and Shuba Y: Ion channels and the hallmarks of cancer. Trends Mol Med 16(3): 107-121, 2010. PMID: 20167536, DOI: 10.1016/j.molmed.2010.01.005

10 Sala-Rabanal M, Yurtsever Z, Nichols CG and Brett TJ: Secreted clca1 modulates TMEM16A to activate $\mathrm{Ca}(2+)$-dependent chloride currents in human cells. Elife 4, 2015. PMID: 25781344, DOI: $10.7554 /$ eLife.05875

11 Sala-Rabanal M, Yurtsever Z, Berry KN, Nichols CG and Brett TJ: Modulation of TMEM16A channel activity by the von Willebrand factor type a (vWA) domain of the calcium-activated chloride channel regulator 1 (CLCA1). J Biol Chem 292(22): 9164-9174, 2017. PMID: 28420732, DOI: 10.1074/jbc.M117. 788232

12 Pawlowski K, Lepisto M, Meinander N, Sivars U, Varga M and Wieslander E: Novel conserved hydrolase domain in the clca family of alleged calcium-activated chloride channels. Proteins 63(3): 424-439, 2006. PMID: 16470849, DOI: 10.1002/ prot.20887

13 Nystrom EEL, Birchenough GMH, van der Post S, Arike L, Gruber AD, Hansson GC and Johansson MEV: Calciumactivated chloride channel regulator 1 (CLCA1) controls mucus expansion in colon by proteolytic activity. EBioMedicine 33: 134-143, 2018. PMID: 29885864, DOI: 10.1016/j.ebiom. 2018.05.031

14 Alevy YG, Patel AC, Romero AG, Patel DA, Tucker J, Roswit WT, Miller CA, Heier RF, Byers DE, Brett TJ and Holtzman MJ: IL-13-induced airway mucus production is attenuated by MAPK13 inhibition. J Clin Invest 122(12): 4555-4568, 2012. PMID: 23187130, DOI: 10.1172/JCI64896

15 Abdel-Ghany M, Cheng HC, Elble RC, Lin H, DiBiasio J and Pauli BU: The interacting binding domains of the beta(4) integrin and calcium-activated chloride channels (CLCAs) in metastasis. J Biol Chem 278(49): 49406-49416, 2003. PMID: 14512419, DOI: $10.1074 /$ jbc.M309086200

16 Abdel-Ghany M, Cheng HC, Elble RC and Pauli BU: Focal adhesion kinase activated by beta(4) integrin ligation to mCLCA1 mediates early metastatic growth. J Biol Chem 277(37): 34391-34400, 2002. PMID: 12110680, DOI: 10.1074/jbc.M205307200

17 Gibson A, Lewis AP, Affleck K, Aitken AJ, Meldrum E and Thompson N: hCLCA1 and mCLCA3 are secreted non-integral membrane proteins and therefore are not ion channels. J Biol Chem 280(29): 27205-27212, 2005. PMID: 15919655, DOI: 10.1074/jbc.M504654200

18 Toda M, Tulic MK, Levitt RC and Hamid Q: A calciumactivated chloride channel (hclca1) is strongly related to IL-9 expression and mucus production in bronchial epithelium of patients with asthma. J Allergy Clin Immunol 109(2): 246-250, 2002. PMID: 11842292. 
19 Nakanishi A, Morita S, Iwashita H, Sagiya Y, Ashida Y, Shirafuji $\mathrm{H}$, Fujisawa Y, Nishimura O and Fujino M: Role of gob-5 in mucus overproduction and airway hyperresponsiveness in asthma. Proc Natl Acad Sci USA 98(9): 5175-5180, 2001. PMID: 11296262, DOI: $10.1073 /$ pnas.081510898

20 Ching JC, Lobanova L and Loewen ME: Secreted hCLCA1 is a signaling molecule that activates airway macrophages. PLoS One 8(12): e83130, 2013. PMID: 24349445, DOI: 10.1371/journal. pone. 0083130

21 Yin Y, Yao S, Hu Y, Feng Y, Li M, Bian Z, Zhang J, Qin Y, Qi X, Zhou L, Fei B, Zou J, Hua D and Huang Z: The immunemicroenvironment confers chemoresistance of colorectal cancer through macrophage-derived IL6. Clin Cancer Res 23(23): 73757387, 2017. PMID: 28928161, DOI: 10.1158/1078-0432.CCR-171283

22 Woo SR, Corrales L and Gajewski TF: Innate immune recognition of cancer. Annu Rev Immunol 33: 445-474, 2015. PMID: 25622193, DOI: 10.1146/annurev-immunol-032414-112043

23 Jabbar KS, Arike L, Verbeke CS, Sadik R and Hansson GC: Highly accurate identification of cystic precursor lesions of pancreatic cancer through targeted mass spectrometry: A phase iic diagnostic study. J Clin Oncol 36(4): 367-375, 2018. PMID: 29166170, DOI: $10.1200 / J C O .2017 .73 .7288$

24 Hoshino M, Morita S, Iwashita H, Sagiya Y, Nagi T, Nakanishi A, Ashida Y, Nishimura O, Fujisawa $\mathrm{Y}$ and Fujino M: Increased expression of the human $\mathrm{Ca}^{2+}$-activated $\mathrm{Cl}$ - channel 1 (CACC1) gene in the asthmatic airway. Am J Respir Crit Care Med 165(8): 1132-1136, 2002. PMID: 11956057, DOI: 10.1164/ajrccm. 165.8 .2107068

25 Agnel M, Vermat T and Culouscou JM: Identification of three novel members of the calcium-dependent chloride channel (CACC) family predominantly expressed in the digestive tract and trachea. FEBS Lett 455(3): 295-301, 1999. PMID: 10437792.

26 Cha JY, Wee J, Jung J, Jang Y, Lee B, Hong GS, Chang BC, Choi YL, Shin YK, Min HY, Lee HY, Na TY, Lee MO and Oh U: Anoctamin 1 (TMEM16A) is essential for testosterone-induced prostate hyperplasia. Proc Natl Acad Sci USA 112(31): 97229727, 2015. PMID: 26153424, DOI: 10.1073/ pnas.1423827112

27 Godse NR, Khan N, Yochum ZA, Gomez-Casal R, Kemp C, Shiwarski DJ, Seethala RS, Kulich S, Seshadri M, Burns TF and Duvvuri U: TMEM16A/ANO1 inhibits apoptosis via downregulation of Bim expression. Clin Cancer Res 23(23): 7324-7332, 2017. PMID: 28899969, DOI: 10.1158/10780432.CCR-17-1561

28 Jia L, Liu W, Guan L, Lu M and Wang K: Inhibition of calciumactivated chloride channel ANO1/TMEM16A suppresses tumor growth and invasion in human lung cancer. PLoS One 10(8): e0136584, 2015. PMID: 26305547, DOI: 10.1371/ journal.pone.0136584

29 Duvvuri U, Shiwarski DJ, Xiao D, Bertrand C, Huang X, Edinger RS, Rock JR, Harfe BD, Henson BJ, Kunzelmann K, Schreiber R, Seethala RS, Egloff AM, Chen X, Lui VW, Grandis JR and Gollin SM: TMEM16A induces MAPK and contributes directly to tumorigenesis and cancer progression. Cancer Res 72(13): 3270-3281, 2012. PMID: 22564524, DOI: 10.1158/ 0008-5472.CAN-12-0475-T

30 Bustin SA, Li SR and Dorudi S: Expression of the Ca2+activated chloride channel genes CLCA1 and CLCA2 is downregulated in human colorectal cancer. DNA Cell Biol
20(6): 331-338, 2001. PMID: 11445004, DOI: 10.1089/ 10445490152122442

31 Yu J, Li X, Zhong C, Li D, Zhai X, Hu W, Guo C, Yuan Y and Zheng S: High-throughput proteomics integrated with gene microarray for discovery of colorectal cancer potential biomarkers. Oncotarget 7(46): 75279-75292, 2016. PMID: 27661117, DOI: $10.18632 /$ oncotarget.12143

32 Yang B, Cao L, Liu B, McCaig CD and $\mathrm{Pu} \mathrm{J}$ : The transition from proliferation to differentiation in colorectal cancer is regulated by the calcium activated chloride channel a1. PLoS One 8(4): e60861, 2013. PMID: 23593331, DOI: 10.1371/ journal.pone.0060861

33 Yang B, Cao L, Liu J, Xu Y, Milne G, Chan W, Heys SD, McCaig $\mathrm{CD}$ and $\mathrm{Pu} \mathrm{J}$ : Low expression of chloride channel accessory 1 predicts a poor prognosis in colorectal cancer. Cancer 121(10): 1570-1580, 2015. PMID: 25603912, DOI: $10.1002 /$ cncr.29235

34 Uhlen M, Oksvold P, Fagerberg L, Lundberg E, Jonasson K, Forsberg M, Zwahlen M, Kampf C, Wester K, Hober S, Wernerus H, Bjorling L and Ponten F: Towards a knowledgebased human protein atlas. Nat Biotecnol 28(12): 1248-1250, 2010. PMID: 21139605, DOI: 10.1038/nbt1210-1248]

35 Chen TJ, He HL, Shiue YL, Yang CC, Lin LC, Tian YF and Chen SH: High chloride channel accessory 1 expression predicts poor prognoses in patients with rectal cancer receiving chemoradiotherapy. Int J Med Sci 15(11): 1171-1178, 2018. PMID: 30123054, DOI: 10.7150/ijms.26685

36 Rottgen TS, Nickerson AJ and Rajendran VM: Calciumactivated $\mathrm{Cl}(-)$ channel: Insights on the molecular identity in epithelial tissues. Int J Mol Sci 19(5): 2018. PMID: 29748496, DOI: $10.3390 / \mathrm{ijms} 19051432$

37 Sui Y, Wu F, Lv J, Li H, Li X, Du Z, Sun M, Zheng Y, Yang L, Zhong L, Zhang $X$ and Zhang G: Identification of the novel TMEM16A inhibitor dehydroandrographolide and its anticancer activity on SW620 cells. PLoS One 10(12): e0144715, 2015. PMID: 26657333, DOI: 10.1371/journal.pone.0144715

38 Sui Y, Sun M, Wu F, Yang L, Di W, Zhang G, Zhong L, Ma Z, Zheng J, Fang $X$ and Ma T: Inhibition of TMEM16A expression suppresses growth and invasion in human colorectal cancer cells. PLoS One 9(12): e115443, 2014. PMID: 25541940, DOI: 10.1371/journal.pone.0115443

$39 \mathrm{Hu}$ D, Ansari D, Zhou Q, Sasor A, Hilmersson KS, Bauden M, Jiang $\mathrm{Y}$ and Andersson R: Calcium-activated chloride channel regulator 1 as a prognostic biomarker in pancreatic ductal adenocarcinoma. BMC Cancer 18(1): 1096, 2018. PMID: 30419838, DOI: 10.1186/s12885-018-5013-2

40 Ansari D, Carvajo M, Bauden M and Andersson R: Pancreatic cancer stroma: Controversies and current insights. Scand J Gastroenterol 52(6-7): 641-646, 2017. PMID: 28276831, DOI: $10.1080 / 00365521.2017 .1293726$

41 Arcangeli A, Crociani O and Bencini L: Interaction of tumour cells with their microenvironment: Ion channels and cell adhesion molecules. A focus on pancreatic cancer. Philos Trans R Soc Lond B Biol Sci 369(1638): 20130101, 2014. PMID: 24493749, DOI: 10.1098/rstb.2013.0101

$42 \mathrm{Xu} \mathrm{Y,} \mathrm{Li} \mathrm{Z,} \mathrm{Jiang} \mathrm{P,} \mathrm{Wu} \mathrm{G,} \mathrm{Chen} \mathrm{K,} \mathrm{Zhang} \mathrm{X} \mathrm{and} \mathrm{Li} \mathrm{X:} \mathrm{The} \mathrm{co-}$ expression of MMP-9 and tenascin-C is significantly associated with the progression and prognosis of pancreatic cancer. Diagn Pathol 10: 211, 2015. PMID: 26652622, DOI: 10.1186/s13000015-0445-3 
43 Li P, Yao H, Zhang Z, Li M, Luo Y, Thompson PR, Gilmour DS and Wang Y: Regulation of p53 target gene expression by peptidylarginine deiminase 4. Mol Cell Biol 28(15): 4745-4758, 2008. PMID: 18505818, DOI: 10.1128/MCB.01747-07

44 Gregory AD and Houghton AM: Tumor-associated neutrophils: New targets for cancer therapy. Cancer Res 71(7): 2411-2416, 2011. PMID: 21427354, DOI: 10.1158/0008-5472.CAN-10-2583

45 Jones LE, Humphreys MJ, Campbell F, Neoptolemos JP and Boyd MT: Comprehensive analysis of matrix metalloproteinase and tissue inhibitor expression in pancreatic cancer: Increased expression of matrix metalloproteinase-7 predicts poor survival. Clin Cancer Res 10(8): 2832-2845, 2004. PMID: 15102692.

46 Sauter DRP, Novak I, Pedersen SF, Larsen EH and Hoffmann EK: ANO1 (TMEM16A) in pancreatic ductal adenocarcinoma (PDAC). Pflugers Arch 467(7): 1495-1508, 2015. PMID: 25163766, DOI: 10.1007/s00424-014-1598-8
47 Frede J, Fraser SP, Oskay-Ozcelik G, Hong Y, Ioana Braicu E, Sehouli J, Gabra H and Djamgoz MB: Ovarian cancer: Ion channel and aquaporin expression as novel targets of clinical potential. Eur J Cancer 49(10): 2331-2344, 2013. PMID: 23683551, DOI: 10.1016/j.ejca.2013.03.016

48 Musrap N, Tuccitto A, Karagiannis GS, Saraon P, Batruch I and Diamandis EP: Comparative proteomics of ovarian cancer aggregate formation reveals an increased expression of calciumactivated chloride channel regulator 1 (clca1). J Biol Chem 290(28): 17218-17227, 2015. PMID: 26004777, DOI: 10.1074/jbc.M115.639773

Received February 15, 2019

Revised February 26, 2019

Accepted February 28, 2019 